\title{
PENGARUH SISTEM AKUNTANSI PENGGAJIAN DAN SISTEM PENGENDALIAN INTERNAL PENGGAJIAN TERHADAP KINERJA KARYAWAN PADA PUSAT PENGELOLAAN PENDAPATAN DAERAH WILAYAH KOTA CIMAHI
}

\author{
Dewi Selviani Yulientinah, Arsuci Cahyaningrum \\ D4 Akuntansi Keuangan, Politeknik Pos Indonesia \\ dewiselviani@poltekpos.ac.id, arsucic@gmail.com
}

\begin{abstract}
ABSTRAK
Pusat Pengelolaan Pendapatan Daerah Wilayah Kota Cimahi merupakan salah satu perangkat daerah pemerintahan Kota Cimahi yang bertugas melaksanakan sebagian tugas Wali Kota dalam hal keuangan daerah pada bidang peningkatan Pendapatan Asli Daerah (PAD). Tujuan penelitian ini adalah untuk mengetahui pengaruh dari Sistem Akuntansi Penggajian dan Sistem Pengendalian Internal Penggajian terhadap Kinerja Karyawan pada Pusat Pengelolaan Pendapatan Daerah Wilayah Kota Cimahi. Penelitian ini terdiri dari tiga variabel yaitu Sistem Akuntansi Penggajian $\left(\mathrm{X}_{1}\right)$, Sistem Pengendalian Internal Penggajian $\left(\mathrm{X}_{2}\right)$ dan Kinerja Karyawan $(\mathrm{Y})$. Metode penelitian yang digunakan adalah metode penelitian kuantitatif dengan rumusan masalah asosiatif dan data yang digunakan yaitu data primer dengan teknik pengumpulan data menggunakan kuesioner. Teknik analisis data yang digunakan yaitu uji validitas, uji reliabilitas, korelasi spearman rank, regresi linier berganda, koefesien determinasi, uji t dan uji f. Hasil dari penelitian ini menunjukkan bahwa terdapat pengaruh secara parsial antara Sistem Akuntansi Penggajian terhadap Kinerja Karyawan dan Sistem Pengendalian Internal Penggajian terhadap Kinerja Karyawan. Terdapat pengaruh secara simultan antara Sistem Akuntansi Penggajian dan Sistem Pengendalian Internal Penggajian terhadap Kinerja Karyawan.

Kata Kunci : Sistem Akuntansi Penggajian, Sistem Pengendalian Internal Penggajian dan Kinerja Karyawan.
\end{abstract}

\begin{abstract}
Pusat Pengelolaan Pendapatan Daerah Wilayah Kota Cimahi is one of the regional apparatus of the Cimahi city government in charge of carrying out some of the tasks of the Mayor in terms of regional finance in the field of increasing Regional Original Income (PAD). The purpose of this study was to determine the effect of the Payroll Accounting System and Payroll Internal Control System on Employee Performance at Pusat Pengelolaan Pendapatan Daerah Wilayah Kota Cimahi. This research consists of three variables, namely Payroll Accounting System $\left(X_{1}\right)$, Payroll Internal Control System $\left(X_{2}\right)$ and Employee Performance (Y). The research method used is a quantitative research method with associative problem formulation and the data used are primary data with data collection techniques using questionnaires. Data analysis techniques used are validity test, reliability test, Spearman rank correlation, multiple linear regression, coefficient of determination, $t$ test and $f$ test. The results of this study indicate that there is a partial influence between the Payroll Accounting System on Employee Performance and the Payroll Internal Control System on Employee Performance. There is a simultaneous influence between the Payroll Accounting System and the Payroll Internal Control System on Employee Performance.

Keywords: Payroll Accounting System, Internal Control System Payroll and Employee Performance.
\end{abstract}




\section{PENDAHULUAN}

Kinerja karyawan mempunyai peran yang penting dalam keberlangsungan sebuah instansi pemerintahan. Kinerja merupakan hasil kerja seseorang dalam suatu periode yang dapat diukur berdasarkan kemampuan menyelesaikan tugas dan tanggung jawab yang telah diberikan. "Dalam kinerja mengandung unsur standar pencapaian yang harus dipenuhi, sehingga bagi yang mencapai standar yang telah ditetapkan berarti berkinerja baik atau sebaliknya bagi yang tidak tercapai dikategorikan berkinerja kurang atau tidak baik" (Kasmir, 2016). Dengan baiknya kinerja karyawan pada sebuah instansi pemerintahan maka akan memberikan dampak yang besar pada instansi pemerintahan tersebut begitu juga sebaliknya apabila kinerja karyawan pada instansi pemerintahan buruk maka akan memberikan dampak yang besar bagi instansi pemerintahan tersebut.

Seperti dilansir dalam (Fajar, 2020) menyatakan bahwa Badan Kepegawaian Negara $(\mathrm{BKN})$ sebagai instansi pembina manajemen kepegawaian senantiasa berupaya mewujudkan enviroment yang mendukung tegaknya sistem merit yang mengedepankan kualifikasi, kompetensi dan kinerja, khususnya dalam penentuan pengisian jabatan di birokrasi. Guna mengukur sejauh mana Instansi Pemerintahan menerapkan manajemen kinerja, BKN melalui Direktorat Kinerja ASN melakukan evaluasi penerapan manajemen kinerja Pegawai Negeri Sipil (PNS) dalam kurun waktu dua tahun (2018-2019). Dari hasil evaluasi tersebut diperoleh data sebagai berikut :

\section{Tabel 1}

Hasil Evaluasi Penerapan Manajemen Kinerja PNS tahun (2018 - 2019)

\begin{tabular}{|c|c|c|}
\hline No & Persentase & Keterangan \\
\hline 1. & $3,3 \%$ & Sangat Baik \\
\hline 2. & $35 \%$ & Baik \\
\hline 3. & $50 \%$ & Cukup \\
\hline 4. & $11,7 \%$ & Buruk \\
\hline
\end{tabular}

Sumber : (Fajar, 2020)

Berdasarkan tabel tersebut hasil evalusi penerapan manajemen kinerja PNS tahun (2018 - 2019) dengan tingkat presentase dengan kategori baik dan cukup sudah cukup tinggi. Salah satu cara untuk dapat menciptakan kinerja karyawan yang baik adalah dengan memberikan motivasi. Menurut (Kasmir, 2016) "secara teori dikatakan bahwa kinerja juga perlu didukung oleh motivasi yang kuat agar kemampuan yang dimiliki dapat dioptimalkan". Motivasi yang dapat meningkatkan kinerja karyawan adalah dengan dilakukannya pelatihan karyawan, pemberian bonus kepada karyawan dan pemberian gaji yang layak kepada karyawan.

Pemberian gaji kepada karyawan pada instansi pemerintahan telah diatur dalam Peraturan Pemerintah (PP) Nomor 15 tahun 2019. Peraturan ini berlaku untuk karyawan dengan status Pegawai Negeri Sipil (PNS) sedangkan untuk pegawai dengan status Non Pegawai Negeri Sipil (Non PNS) pemberian gaji berdasarkan besaran Upah Minimum Regional (UMR). Pemberian gaji kepada Pegawai Negeri Sipil (PNS) diatur berdasarkan pangkat, golongan dan masa kerja pegawai tersebut.

Pada praktiknya sistem penggajian Pegawai negeri Sipil (PNS) meggunakan sistem pangkat dan golongan. Sistem penggajian merupakan salah satu bagian dari sistem akuntansi. Sistem akuntansi penggajian dapat digunakan untuk mengetahui karyawan yang berkualitas atau tidak. Untuk dapat menjaga kualitas dari karyawan tersebut maka diperlukan sistem pengendalian internal penggajian. Sistem pengendalian internal penggajian dapat digunakan sebagai acuan dalam melakukan sistem penggajian yang bertujuan untuk mendorong dipatuhinya kebijakan yang dibuat oleh manajemen. Sistem pengendalian internal penggajian dan sistem akuntansi penggajian merupakan upaya yang dilakukan oleh sebuah instansi pemerintah dalam meningkatkan kinerja karyawan. Sistem 
akuntansi penggajian, sistem pengendalian internal penggajian dan kinerja karyawan memiliki fungsi yang sangat penting dalam sebuah instansi pemerintah. Salah satunya pada Pusat Pengelolaan Pendapatan Daerah Kota Cimahi.

Berdasarkan penjelasan sebelumnya maka identifikasi masalah yang dapat diteliti yaitu :

1. Apakah sistem akuntansi penggajian mempengaruhi kinerja karyawan pada Pusat Pengelolaan Pendapatan Daerah Wilayah Kota Cimahi ?

2. Apakah sistem pengendalian internal penggajian mempengaruhi kinerja karyawan pada Pusat Pengelolaan Pendapatan Daerah Wilayah Kota Cimahi ?

3. Apakah terdapat pengaruh antara sistem akuntansi penggajian dan sistem pengendalian internal penggajian terhadap kinerja karyawan pada Pusat Pengelolaan Pendapatan Daerah Wilayah Kota Cimahi ?

\section{Sistem Akuntansi Penggajian}

Sistem akuntansi penggajian digunakan untuk menangani transaksi pembayaran atas penyerahan jasa yang dilakukan oleh karyawan yang mempunyai jenjang jabatan manajer" (Mulyadi, 2017).

Sistem penggajian adalah "serangkaian aktivitas bisnis dan kegiatan pengolahan data yang terkait yang berhubungan dengan pengelolaan karyawan perusahaan secara efektif" (Krismiaji, 2020).

\section{Sistem Pengendalian Internal Penggajian}

Menurut (Mulyadi, 2017) sistem pengendalian internal meliputi struktur-struktur organisasi, metode dan ukuran-ukuran yang dikoordinasikan untuk menjaga aset organisasi, mengecek ketelitian dan keandalan data akuntansi, mendorong efisiensi dan mendorong dipatuhinya kebijakan manajemen.

Menurut (Krismiaji, 2020) pengendalian internal adalah organisasi dan metode yang digunakan untuk menjaga atau melindungi aktiva, menghasilkan informasi yang akurat dan dapat dipercaya, perbaiki efisiensi dan untuk mendorong ditaatinya kebijakan manajemen.

\section{Kinerja Karyawan}

Menurut (Afandi, 2018) "kinerja adalah hasil kerja yang dapat dicapai oleh seseorang atau kelompok orang dalam suatu perusahaan sesuai dengan wewenang dan tanggung jawab masing-masing dalam upaya pencapaian tujuan organisasi secara ilegal, tidak melanggar hukum dan tidak bertentangan dengan moral dan etika".

Gibson dalam (Kasmir, 2016) "menyatakan bahwa kinerja individu adalah dasar kinerja organisasi yang sangat dipengaruhi oleh karakteristik individu, motivasi individu, pengharapan, dan penilaian yang dilakukan oleh manajemen terhadap pencapaian hasil kerja individu".

\section{METODE PENELITIAN \\ Jenis Penelitian}

Jenis penelitian yang digunakan dalam penelitian ini yaitu jenis penelitian kuantitatif dengan metode penelitian kuantitatif karena data yang digunakan berupa angka dan analisis menggunakan statistik berdasarkan hasil survei yang dilakukan pada objek penelitian. Menurut (Sugiyono, 2019) metode penelitian kuantitatif dapat diartikan sebagai metode penelitian yang berlandaskan pada filsafat positivisme digunakan untuk meneliti pada populasi atau sampel tertentu, pengumpulan data menggunakan instrumen penelitian, analisis data bersifat kuantitatif atau statistik dengan tujuan untuk menguji hipotesis yang telah ditetapkan.

Pada penelitian ini rumusan masalah yang digunakan adalah rumusan masalah asosiatif dengan bentuk hubungan kausal yang bersifat sebab akibat. Menurut (Sugiyono, 2019) "rumusan masalah asosiatif adalah suatu rumusan masalah penelitian yang bersifat 
menanyakan hubungan antara dua variabel atau lebih". Penggunaan hubungan kausal pada penelitian ini sebab terdapat variabel independen (variabel yang mempengaruhi) dan variabel dependen (variabel yang dipengaruhi).

\section{Operasional Variabel}

Variabel yang digunakan, indikator-indikator yang digunakan, skala pengukuran variabel yang digunakan, dan alat analisis yang digunakan terdapat pada tabel berikut :

\section{Tabel 2}

Operasional Variabel

\begin{tabular}{|c|c|c|c|c|}
\hline No & Variabel & Indikator & $\begin{array}{l}\text { Skala } \\
\text { Ukur }\end{array}$ & Alat Analisis \\
\hline 1. & $\begin{array}{l}\mathrm{X}_{1} \text { : Sistem } \\
\text { Akuntansi } \\
\text { Penggajian }\end{array}$ & $\begin{array}{rc}\text { 1. } & \text { Analisa } \\
& \text { Pekerjaan } \\
\text { 2. } & \text { Ikatan } \\
& \text { Kerjasama } \\
\text { 3. } & \text { Survey } \\
& \text { Gaji } \\
\text { 4. } & \text { Menentuka } \\
& \text { n Harga dari } \\
& \text { Tiap } \\
& \text { Pekerjaan } \\
& \\
\text { William B. Wether } \\
\text { dan Keith Davin } \\
\text { dalam (Apriansyah, } \\
\text { 2019) }\end{array}$ & Ordinal & $\begin{array}{ll}\text { 1. } & \text { Uji Validitas } \\
\text { 2. Uji Reliabilitas } \\
\text { 3. } & \text { Korelasi } \\
\text { 4pearman Rank } \\
\text { 4. } \text { Regresi Linier } \\
\text { Berganda } \\
\text { 5. } \text { Koefesien } \\
\text { Determinasi } \\
\text { 6. Uji t } \\
\text { 7. Uji f }\end{array}$ \\
\hline 2. & \begin{tabular}{l}
\multicolumn{1}{c}{$\mathrm{X}_{2}:$ Sistem } \\
Pengendalian \\
Internal \\
Penggajian
\end{tabular} & $\begin{array}{cc}\text { 1. } & \text { Organisasi } \\
\text { 2. } & \text { Sistem } \\
\text { Otorisasi } \\
\text { 3. } & \text { Prosedur } \\
\text { Pencatatan } \\
\text { 4. } & \text { Praktik } \\
& \text { yang Sehat } \\
& \\
\text { (Mulyadi, 2016) }\end{array}$ & Ordinal & $\begin{array}{ll}\text { 1. } & \text { Uji Validitas } \\
\text { 2. Uji Reliabilitas } \\
\text { 3. } & \text { Korelasi } \\
& \text { Spearman Rank } \\
\text { 4. } & \text { Regresi Linier } \\
& \text { Berganda } \\
\text { 5. } & \text { Koefesien } \\
& \text { Determinasi } \\
\text { 6. Uji t } \\
\text { 7. Uji f } \\
\end{array}$ \\
\hline 3. & $\begin{array}{l}\text { Y : Kinerja } \\
\text { Karyawan }\end{array}$ & $\begin{array}{cl}\text { 1. } & \text { Kuantitas } \\
& \text { Hasil Kerja } \\
\text { 2. } & \text { Kualitas } \\
& \text { Hasil Kerja } \\
\text { 3. } & \text { Efisiensi } \\
\text { dalam } \\
\text { Melaksanaka } \\
\text { n Tugas } \\
\text { 4. Disiplin } \\
\text { Kerja } \\
\text { 5. Inisiatif } \\
\text { 6. } & \text { Ketelitian } \\
\end{array}$ & Ordinal & $\begin{array}{ll}\text { 1. } & \text { Uji Validitas } \\
\text { 2. Uji Reliabilitas } \\
\text { 3. } & \text { Korelasi } \\
\text { 4pearman Rank } & \text { Spegresi Linier } \\
\text { 4. } & \text { Regreanda } \\
& \text { Berganda } \\
\text { 5. } & \text { Koefesien } \\
& \text { Determinasi } \\
\text { 6. Uji t } \\
\text { 7. Uji f }\end{array}$ \\
\hline
\end{tabular}

Tabel 3

Operasional Variabel (Lanjutan) 


\begin{tabular}{|c|c|c|c|c|}
\hline No & Variabel & Indikator & $\begin{array}{c}\text { Skala } \\
\text { Ukur }\end{array}$ & Alat Analisis \\
\hline & & $\begin{aligned} & \text { 7. } \text { Kepemimpi } \\
& \text { nan } \\
& \text { 8. Kejujuran } \\
& \text { 9. Kreativitas } \\
& \text { (Afandi, 2018) }\end{aligned}$ & & \\
\hline
\end{tabular}

Sumber : Data Diolah

\section{Teknik Pengumpulan Data}

Dalam penelitian ini teknik pengumpulan data yang digunakan yaitu kuesioner (angket). Menurut (Sugiyono, 2019) kuesioner merupakan teknik pengumpulan data yang dilakukan dengan cara memberi seperangkat pertanyaan atau pernyataan tertulis kepada responden untuk di jawabnya. Selain itu kuesioner juga cocok digunakan bila jumlah responden cukup besar dan tersebar di wilayah yang luas.

\section{Populasi dan Sampel}

Menurut (Sugiyono, 2019) mendefinisikan bahwa "populasi adalah wilayah generalisasi yang terdiri atas obyek atau subyek yang mempunyai kuantitas dan karakteristik tertentu yang ditetapkan oleh peneliti untuk dipelajari dan kemudian ditarik kesimpulannya".

Populasi pada penelitian ini adalah para pegawai yang terlibat dengan proses penggajian pada Pusat Pengelolaan Pendapatan Daerah Wilayah Kota Cimahi. Jumlah populasi adalah sebanyak 35 pegawai dengan rincian sebagai berikut.

\section{Tabel 4}

\section{Daftar Pegawai Pusat Pengelolaan Pendapatan Daerah Wilayah Kota Cimahi}

\begin{tabular}{|c|l|c|}
\hline No & \multicolumn{1}{|c|}{ Sub Unit Kerja } & Jumlah \\
\hline 1. & UPTD P3D Wil. Kota Cimahi & 1 \\
\hline 2. & Sub Bagian Tata Usaha & 5 \\
\hline 3. & Seksi Pendataan \& Penetapan & 8 \\
\hline 4. & Seksi Penerimaan \& Penagihan & 3 \\
\hline 5. & Tenaga Teknis Pelaksanaan Kegiatan & 2 \\
\hline 6. & Tenaga Penunjang Tugas Fungsi & 16 \\
\hline \multicolumn{2}{|c|}{ Total } & $\mathbf{3 5}$ \\
\hline
\end{tabular}

Sumber : Pusat Pengelolaan Pendapatan Daerah Wilayah Kota Cimahi

Menurut (Sugiyono, 2019) sampel adalah bagian dari jumlah dan karakteristik yang dimiliki oleh populasi tersebut. Apa yang dipelajari dari sampel itu kesimpulannya akan dapat diberlakukan untuk populasi. Untuk itu sampel yang diambil dari populasi harus betul-betul representatif (mewakili).

\section{Teknik Sampling}

Dalam penelitian ini teknik sampling yang digunakan yaitu dengan metode nonprobability sampling dengan pendekatan sampling total. Menurut (Sugiyono, 2019) nonprobability sampling adalah teknik pengambilan sampel yang tidak memberikan peluang/kesempatan sama bagi setiap unsur anggota populasi untuk dipilih menjadi sampel dan sampling total adalah teknik pengambilan sampel dimana seluruh anggota populasi dijadikan sampel semua.

Kriteria pertimbangan sampel yang telah ditentukan adalah sebagai berikut :

1. Pegawai yang berstatus karyawan aktif pada Pusat Pengelolaan Pendapatan Daerah Wilayah Kota Cimahi.

2. Pegawai yang terlibat secara langsung dengan proses penggajian pada Pusat Pengelolaan Pendapatan Daerah Wilayah Kota Cimahi. 


\section{Teknik Analisis Data}

Dalam penelitian ini analisis data yang digunakan adalah analisis kuantitatif karena data yang diolah berupa angka dari hasil penyebaran kuesioner dengan tujuan untuk menguji hipotesis yang telah ditentukan maka dari itu dilakukan pengujian menggunakan teknik analisis seperti uji validitas, uji reliabilitas, korelasi spearman rank, regresi linier berganda, koefesian determinasi, uji t dan uji f yang dilakukan berdasarkan data yang diperoleh menggunakan alat bantu SPSS versi 26.0 agar data yang dihasilkan lebih akurat.

\section{HASIL DAN PEMBAHASAN}

\section{Hasil Uji Validitas}

Tabel 5

Hasil Uji Validitas Variabel $\mathrm{X}_{1}$ Sistem Akuntansi Penggajian

\begin{tabular}{|c|c|c|c|c|}
\hline No & Pernyataan & $\mathbf{r}_{\text {hitung }}$ & $\mathbf{r}_{\text {tabel }}$ & Keterangan \\
\hline 1. & Item 1 & 0,619 & 0,334 & Valid \\
\hline 2. & Item 2 & 0,688 & 0,334 & Valid \\
\hline 3. & Item 3 & 0,527 & 0,334 & Valid \\
\hline 4. & Item 4 & 0,686 & 0,334 & Valid \\
\hline 5. & Item 5 & 0,486 & 0,334 & Valid \\
\hline 6. & Item 6 & 0,536 & 0,334 & Valid \\
\hline 7. & Item 7 & 0,550 & 0,334 & Valid \\
\hline 8. & Item 8 & 0,559 & 0,334 & Valid \\
\hline
\end{tabular}

Sumber : Data diolah

Berdasarkan tabel sebelumnya telah menunjukan semua pernyataan variabel $\mathrm{X}_{1}$ Sistem Akuntansi Penggajian dinyatakan valid dengan nilai $r_{\text {hitung }}>r_{\text {tabel }}(0,334)$. Dari hasil tersebut dapat disimpulkan bahwa setiap pernyataan dapat digunakan dalam peneitian.

Tabel 6

Hasil Uji Validitas Variabel $\mathbf{X}_{2}$ Sistem Pengendalian Internal Penggajian

\begin{tabular}{|c|c|c|c|c|}
\hline No & Pernyataan & $\mathbf{r}_{\text {hitung }}$ & $\mathbf{r}_{\text {tabel }}$ & Keterangan \\
\hline 1. & Item 1 & 0,539 & 0,334 & Valid \\
\hline 2. & Item 2 & 0,638 & 0,334 & Valid \\
\hline 3. & Item 3 & 0,833 & 0,334 & Valid \\
\hline 4. & Item 4 & 0,728 & 0,334 & Valid \\
\hline 5. & Item 5 & 0,543 & 0,334 & Valid \\
\hline 6. & Item 6 & 0,635 & 0,334 & Valid \\
\hline 7. & Item 7 & 0,529 & 0,334 & Valid \\
\hline 8. & Item 8 & 0,511 & 0,334 & Valid \\
\hline 9. & Item 9 & 0,736 & 0,334 & Valid \\
\hline
\end{tabular}

Sumber : Data diolah

Berdasarkan tabel sebelumnya telah menunjukan semua pernyataan variabel $\mathrm{X}_{2}$

Sistem Pengendalian Internal Penggajian dinyatakan valid dengan nilai $r$ hitung $>r$ tabel $(0,334)$. Dari hasil tersebut dapat disimpulkan bahwa setiap pernyataan dapat digunakan dalam penelitian.

Tabel 7

Hasil Uji Validitas Variabel Y Kinerja Karyawan

\begin{tabular}{|c|c|c|c|c|}
\hline No & Pernyataan & $\mathbf{r}_{\text {hitung }}$ & $\mathbf{r}_{\text {tabel }}$ & Keterangan \\
\hline 1. & Item 1 & 0,547 & 0,334 & Valid \\
\hline 2. & Item 2 & 0,674 & 0,334 & Valid \\
\hline 3. & Item 3 & 0,672 & 0,334 & Valid \\
\hline 4. & Item 4 & 0,642 & 0,334 & Valid \\
\hline 5. & Item 5 & 0,747 & 0,334 & Valid \\
\hline
\end{tabular}




\begin{tabular}{|c|c|c|c|c|}
\hline 6. & Item 6 & 0,677 & 0,334 & Valid \\
\hline 7. & Item 7 & 0,389 & 0,334 & Valid \\
\hline 8. & Item 8 & 0,520 & 0,334 & Valid \\
\hline 9. & Item 9 & 0,447 & 0,334 & Valid \\
\hline 10. & Item 10 & 0,367 & 0,334 & Valid \\
\hline 11. & Item 11 & 0,525 & 0,334 & Valid \\
\hline 12. & Item 12 & 0,353 & 0,334 & Valid \\
\hline 13. & Item 13 & 0,533 & 0,334 & Valid \\
\hline 14. & Item 14 & 0,432 & 0,334 & Valid \\
\hline 15. & Item 15 & 0,533 & 0,334 & Valid \\
\hline 16. & Item 16 & 0,461 & 0,334 & Valid \\
\hline 17. & Item 17 & 0,545 & 0,334 & Valid \\
\hline 18. & Item 18 & 0,508 & 0,334 & Valid \\
\hline 19. & Item 19 & 0,459 & 0,334 & Valid \\
\hline 20. & Item 20 & 0,761 & 0,334 & Valid \\
\hline
\end{tabular}

Sumber : Data diolah

Berdasarkan tabel sebelumnya telah menunjukan semua pernyataan variabel $\mathrm{Y}$ Kinerja Karyawan dinyatakan valid dengan nilai $r_{\text {hitung }}>r_{\text {tabel }}(0,334)$. Dari hasil tersebut dapat disimpulkan bahwa setiap pernyataan dapat digunakan dalam penelitian.

\section{Uji Reliabilitas}

Tabel 8

Hasil Uji Reliabilitas Variabel $X_{1}$ Sistem Akuntansi Penggajian

\begin{tabular}{|c|c|c|c|c|}
\hline No & Pernyataan & $\begin{array}{c}\text { Cronbach's } \\
\text { Alpha }\end{array}$ & $\begin{array}{c}\text { Cronbach's } \\
\text { Alpha Standard }\end{array}$ & Keterangan \\
\hline 1. & Item 1 & 0,713 & 0,60 & Reliabel \\
\hline 2. & Item 2 & 0,706 & 0,60 & Reliabel \\
\hline 3. & Item 3 & 0,721 & 0,60 & Reliabel \\
\hline 4. & Item 4 & 0,703 & 0,60 & Reliabel \\
\hline 5. & Item 5 & 0,726 & 0,60 & Reliabel \\
\hline 6. & Item 6 & 0,721 & 0,60 & Reliabel \\
\hline 7. & Item 7 & 0,720 & 0,60 & Reliabel \\
\hline 8. & Item 8 & 0,719 & 0,60 & Reliabel \\
\hline
\end{tabular}

Sumber : Data diolah

Berdasarkan tabel sebelumnya telah menunjukan semua pernyataan variabel $\mathrm{X}_{1}$ Sistem Akuntansi Penggajian dinyatakan reliabel dengan nilai Alpha $>0,60$. Dari hasil tersebut dapat disimpulkan bahwa setiap pernyataan yang digunakan dalam penelitian.

Tabel 9

Hasil Uji Reliabilitas Variabel $\mathbf{X}_{2}$ Sistem Pengendalian Internal Penggajian

\begin{tabular}{|c|c|c|c|c|}
\hline No & Pernyataan & $\begin{array}{c}\text { Cronbach's } \\
\text { Alpha }\end{array}$ & $\begin{array}{c}\text { Cronbach's } \\
\text { Alpha Standard }\end{array}$ & Keterangan \\
\hline 1. & Item 1 & 0,742 & 0,60 & Reliabel \\
\hline 2. & Item 2 & 0,737 & 0,60 & Reliabel \\
\hline 3. & Item 3 & 0,714 & 0,60 & Reliabel \\
\hline 4. & Item 4 & 0,727 & 0,60 & Reliabel \\
\hline 5. & Item 5 & 0,741 & 0,60 & Reliabel \\
\hline 6. & Item 6 & 0,730 & 0,60 & Reliabel \\
\hline 7. & Item 7 & 0,741 & 0,60 & Reliabel \\
\hline 8. & Item 8 & 0,742 & 0,60 & Reliabel \\
\hline 9. & Item 9 & 0,726 & 0,60 & Reliabel \\
\hline
\end{tabular}


Sumber : Data diolah

Berdasarkan tabel sebelumnya telah menunjukan semua pernyataan variabel $\mathrm{X}_{2}$ Sistem Pengendalian Internal Penggajian dinyatakan reliabel dengan nilai Alpha > 0,60. Dari hasil tersebut dapat disimpulkan bahwa setiap pernyataan yang digunakan pada penelitian.

\section{Tabel 10}

Hasil Uji Reliabilitas Variabel Y Kinerja Karyawan

\begin{tabular}{|c|c|c|c|c|}
\hline No & Pernyataan & $\begin{array}{c}\text { Cronbach's } \\
\text { Alpha }\end{array}$ & $\begin{array}{c}\text { Cronbach's } \\
\text { Alpha } \\
\text { Standard }\end{array}$ & Keterangan \\
\hline 1. & Item 1 & 0,730 & 0,60 & Reliabel \\
\hline 2. & Item 2 & 0,726 & 0,60 & Reliabel \\
\hline 3. & Item 3 & 0,726 & 0,60 & Reliabel \\
\hline 4. & Item 4 & 0,727 & 0,60 & Reliabel \\
\hline 5. & Item 5 & 0,724 & 0,60 & Reliabel \\
\hline 6. & Item 6 & 0,726 & 0,60 & Reliabel \\
\hline 7. & Item 7 & 0,734 & 0,60 & Reliabel \\
\hline 8. & Item 8 & 0,731 & 0,60 & Reliabel \\
\hline 9. & Item 9 & 0,733 & 0,60 & Reliabel \\
\hline 10. & Item 10 & 0,735 & 0,60 & Reliabel \\
\hline 11. & Item 11 & 0,728 & 0,60 & Reliabel \\
\hline 12. & Item 12 & 0,735 & 0,60 & Reliabel \\
\hline 13. & Item 13 & 0,731 & 0,60 & Reliabel \\
\hline 14. & Item 14 & 0,734 & 0,60 & Reliabel \\
\hline 15. & Item 15 & 0,732 & 0,60 & Reliabel \\
\hline 16. & Item 16 & 0,733 & 0,60 & Reliabel \\
\hline 17. & Item 17 & 0,730 & 0,60 & Reliabel \\
\hline 18. & Item 18 & 0,732 & 0,60 & Reliabel \\
\hline 19. & Item 19 & 0,733 & 0,60 & Reliabel \\
\hline 20. & Item 20 & 0,723 & 0,60 & Reliabel \\
\hline
\end{tabular}

Sumber : Data diolah

Berdasarkan tabel sebelumnya telah menunjukan semua pernyataan variabel $\mathrm{Y}$ Kinerja Karyawan dinyatakan reliabel dengan nilai Alpha > 0,60. Dari hasil tersebut dapat disimpulkan bahwa setiap pernyataan yang digunakan dalam penelitian.

\section{Korelasi Spearman Rank}

\begin{tabular}{|c|c|c|c|c|c|}
\hline & & & X1 & $\mathrm{X} 2$ & $Y$ \\
\hline \multirow[t]{6}{*}{ Spearman's rho } & \multirow[t]{3}{*}{$\mathrm{x} 1$} & Correlation Coefficient & 1,000 &, $790^{\star \star}$ &, $773^{\mathrm{k}}$ \\
\hline & & Sig. (1-tailed) & . &, 000 &, 000 \\
\hline & & $\mathrm{N}$ & 35 & 35 & 35 \\
\hline & \multirow[t]{3}{*}{$\mathrm{x} 2$} & Correlation Coefficient &, $790^{\mathrm{*}}$ & 1,000 &, $750^{\pi \prime}$ \\
\hline & & Sig. (1-tailed) &, 000 & . &, 000 \\
\hline & & $\mathrm{N}$ & 35 & 35 & 35 \\
\hline \multicolumn{6}{|c|}{ Gambar 1 Hasil Korelasi Spearman Rank } \\
\hline & & Sig. (1-tailed) &, 000 &, 000 & . \\
\hline & & $\mathrm{N}$ & 35 & 35 & 35 \\
\hline
\end{tabular}

Sumber : SPSS versi 26

Berdasarkan gambar sebelumnya dapat diketahui bahwa nilai korelasi Spearman

Rank antara Sistem Akuntansi Penggajian $\left(\mathrm{X}_{1}\right)$ terhadap Kinerja Karyawan $(\mathrm{Y})$ sebesar 0,773 nilai tersebut menginterpretasikan hubungan atau besaran nilai berada pada kategori 
"kuat". Nilai korelasi Spearman Rank antara Sistem Pengendalian Internal Penggajian $\left(\mathrm{X}_{2}\right)$ terhadap Kinerja Karyawan (Y) sebesar 0,750 nilai tersebut menginterpretasikan hubungan atau besaran berada pada kategori "kuat".

\section{Regresi Linier Berganda}

\begin{tabular}{|c|c|c|c|c|c|c|}
\hline \multirow[b]{2}{*}{ Model } & & \multicolumn{2}{|c|}{ Unstandardized Coefficients } & \multirow{2}{*}{$\begin{array}{c}\text { Standardized } \\
\text { Coefficients } \\
\text { Beta }\end{array}$} & \multirow[b]{2}{*}{$\mathrm{t}$} & \multirow[b]{2}{*}{ Sig. } \\
\hline & & $\mathrm{B}$ & Std. Error & & & \\
\hline \multirow[t]{2}{*}{1} & (Constant) & 23,139 & 8,064 & & 2,869 &, 007 \\
\hline & $v_{1}$ & 1125 & 275 & EกA & 2 กาo & nกF \\
\hline
\end{tabular}

Sun

Gambar 2 Hasil Analisis Regresi Linier Berganda

a. Dependent Variable: $Y \quad$ besar

23,139, nilai koefesien regresi $\left(b_{1}\right)$ sebesar 1,135 dan nilai koefesien regresi $\left(b_{2}\right)$ sebesar 0,657 . Berdasarkan nilai-nilai tersebut maka didapat persamaan regresi linier berganda yaitu :

Keterangan :

$$
Y=23,139+1,135 X_{1}+0,657 X_{2}
$$

$\mathrm{Y} \quad=$ Kinerja Karyawan

$\mathrm{X}_{1} \quad=$ Sistem Akuntansi Penggajian

$\mathrm{X}_{2} \quad=$ Sistem Pengendalian Internal Penggajian

Berdasarkan persamaan analisis regresi linier barganda tersebut dapat disimpulkan bahwa :

1. Jika variabel $X_{1}$ Sistem Akuntansi Penggajian dan variabel $X_{2}$ Sistem Pengendalian Internal Penggajian mempunyai nilai 0 maka nilai variabel Y Kinerja Karyawan adalah sebesar 23,139.

2. Nilai koefesien regresi variabel $X_{1}$ Sistem Akuntansi Penggajian sebesar 1,135. Nilai tersebut dapat diartikan bahwa jika variabel $X_{1}$ Sistem Akuntansi Penggajian mengalami kenaikan sebesar 1 satuan maka nilai variabel Y Kinerja Karyawan akan mengalami peningkatan sebesar 1,135. Nilai koefesien regresi yang positif memiliki arti bahwa terjadi hubungan positif.

3. Nilai koefesien regresi variabel $\mathrm{X}_{2}$ Sistem Pengendalian Internal Penggajian sebesar 0,657. Nilai tersebut dapat diartikan bahwa jika variabel $\mathrm{X}_{2}$ Sistem Pengendalian Internal Penggajian mengalami kenaikan sebesar 1 satuan maka nilai variabel Y Kinerja Karyawan akan mengalami peningkatan sebesar 0,657. Nilai koefesien regresi yang positif memiliki arti bahwa terjadi hubungan positif.

\section{Koefesien Determinasi}

\begin{tabular}{|c|c|c|c|c|}
\hline Mode & $\mathrm{R}$ & R Square & $\begin{array}{c}\text { Adjusted R } \\
\text { Square }\end{array}$ & $\begin{array}{l}\text { Std. Error of } \\
\text { the Estimate }\end{array}$ \\
\hline 1 & $8.30^{\mathrm{a}}$ & 68.9 & 669 & 3125 \\
\hline
\end{tabular}

Sumber :

a. Predictors: (Constant), X2, X1

Beraasarкan gambar tersebut aарат аıкетаnuı panwa nıаı $\mathrm{K}$ square sebesar 0,689 yang menunjukan bahwa besaran pengaruh variabel $\mathrm{X}_{1}$ Sistem Akuntansi Penggajian dan variabel $\mathrm{X}_{2}$ Sistem Pengendalian Internal Penggajian terhadap variabel $\mathrm{Y}$ Kinerja Karyawan sebesar $68,9 \%$ sedangkan sisanya yaitu sebesar $31,1 \%$ dipengaruhi oleh variabel lain yang tidak diteliti dalam penelitian ini.

Uji t

\begin{tabular}{|c|c|c|c|c|c|c|}
\hline \multirow[b]{2}{*}{ Mode } & & \multicolumn{2}{|c|}{ Unstandardized Coefficients } & \multirow{2}{*}{$\begin{array}{c}\text { Standardized } \\
\text { Coefficients } \\
\text { Beta }\end{array}$} & \multirow[b]{2}{*}{$\mathrm{t}$} & \multirow[b]{2}{*}{ Sig. } \\
\hline & & $\mathrm{B}$ & Std. Error & & & \\
\hline \multirow[t]{3}{*}{1} & (Constant) & 23,139 & 8,064 & & 2,869 &, 007 \\
\hline & $\mathrm{X} 1$ & 1,135 &, 375 &, 504 & 3,029 &, 005 \\
\hline & $\times 2$ &, 657 &, 296 &, 369 & 2,219 &, 034 \\
\hline
\end{tabular}

a. Dependent Variable: $Y$ 
Sumber : SPSS versi 26

Berdasarkan gambar tersebut dapat diketahui bahwa :

1. Hasil pengujian yang telah dilakukan dapat diketahui bahwa nilai $t$ hitung sebesar 3,029 dan signifikansi sebesar 0,005. Berdasarkan data tersebut dapat diketahui bahwa $\mathrm{t}_{\text {hitung }}(3,029)>\mathrm{t}$ tabel $(1,692)$ dan nilai sig $0,005<0,05$ yang memiliki arti bahwa $\mathrm{Ha}_{1}$ diterima dan $\mathrm{Ho}_{1}$ ditolak. Hal ini menjelaskan bahwa terdapat pengaruh antara variabel $\mathrm{X}_{1}$ Sistem Akuntansi Penggajian terhadap variabel Y Kinerja Karyawan.

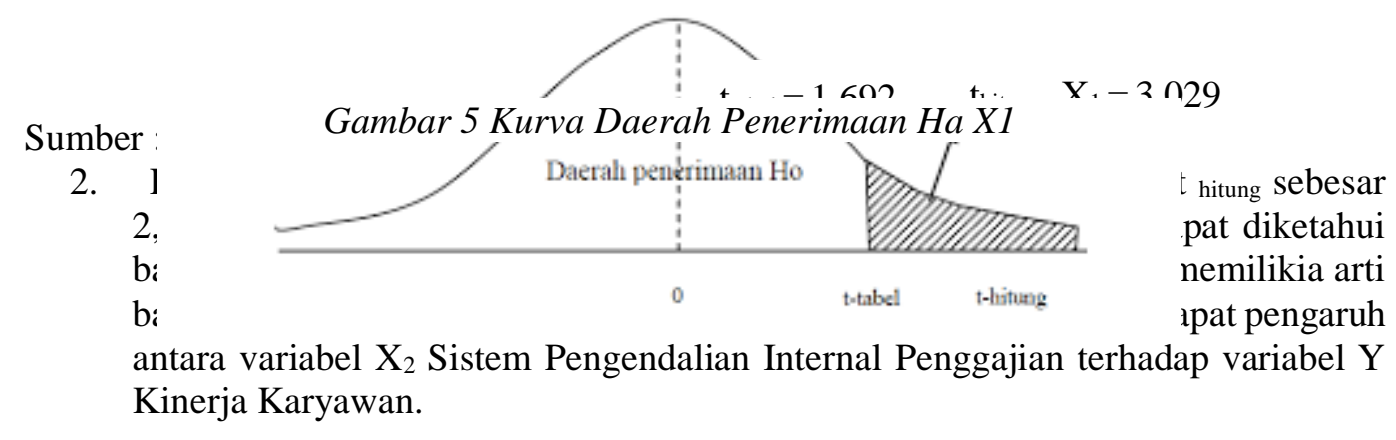

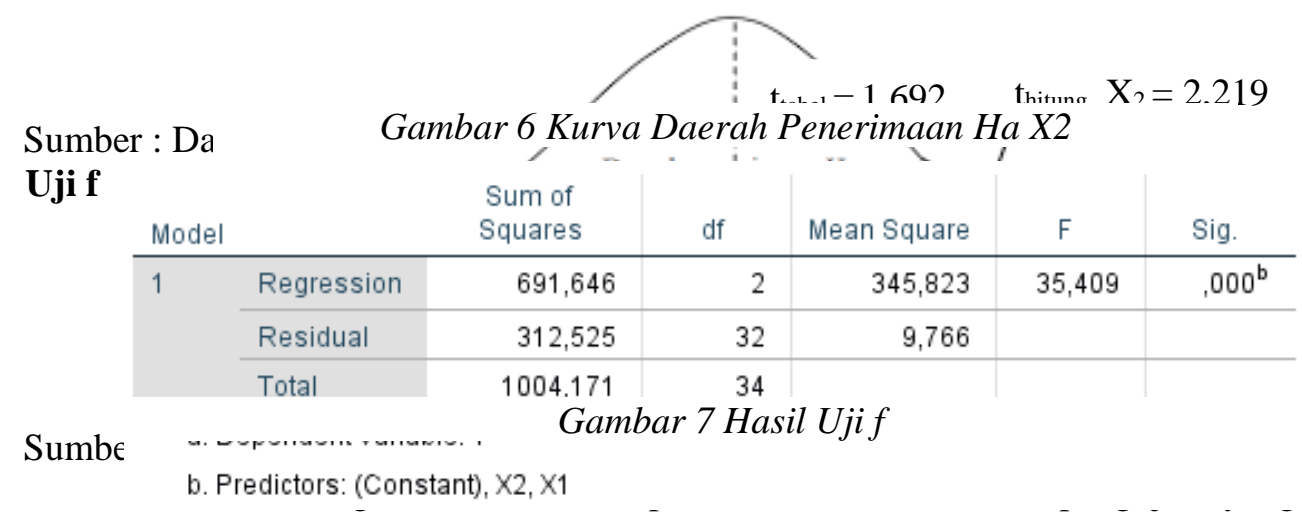

dilakukan dapat diketahui bahwa nilai f hitung sebesar 35,409 dan signifikansi sebesar 0,000 . Berdasarkan data tersebut dapat diketahui bahwa $\mathrm{f}_{\text {hitung }}(35,409)>\mathrm{f}_{\text {tabel }}(3,30)$ dan nilai sig $0,000<0,05$ yang memiliki arti bahwa $\mathrm{Ha}_{3}$ diterima dan $\mathrm{Ho}_{3}$ ditolak. Hal ini menjelaskan bahwa terdapat pengaruh secara bersama-sama (simultan) antara variabel $\mathrm{X}_{1}$ Sistem Akuntansi Penggajian dan variabel $\mathrm{X}_{2}$ Sistem Pengendalian Internal Penggajian terhadap variabel Y Kinerja Karyawan.

\section{KESIMPULAN}

\section{Kesimpulan}

1. Hasil uji hipotesis secara parsial antara Sistem Akuntansi Penggajian dan Kinerja Karyawan menunjukkan bahwa $\mathrm{Ha}_{1}$ diterima dan $\mathrm{Ho}_{1}$ ditolak. Berdasarkan hal tersebut maka terdapat pengaruh antara Sistem Akuntansi Penggajian terhadap Kinerja Karyawan pada Pusat Pengelolaan Pendapatan Daerah Wilayah Kota Cimahi.

2. Hasil uji hipotesis secara parsial antara Sistem Penggendalian Internal Penggajian terhadap Kinerja Karyawan menunjukkan bahwa $\mathrm{Ha}_{2}$ diterima dan $\mathrm{Ho}_{2}$ ditolak. Berdasarkan hal tersebut maka terdapat pengaruh antara Sistem Pengendalian 
Internal Penggajian terhadap Kinerja Karyawan pada Pusat Pengaelolaan Pendapatan Daerah Wilayah Kota Cimahi.

3. Hasil uji hipotesis secara simultan antara Sistem Akuntansi Penggajian dan Sistem Penggendalian Internal Penggajian terhadap Kinerja Karyawan menunjukkan bahwa $\mathrm{Ha}_{3}$ diterima dan $\mathrm{Ho}_{3}$ ditolak. Berdasarkan hal tersebut maka terdapat pengaruh antara Sistem Akuntansi Penggajian dan Sistem Pengendalian Internal Penggajian terhadap Kinerja Karyawan pada Pusat Pengaelolaan Pendapatan Daerah Wilayah Kota Cimahi.

Saran

Berdasarkan hasil analisis mengenai identifikasi masalah, hipotesis dan hasil pengujian yang dilakukan maka penulis memberikan saran yang dapat dipertimbangkan bagi penulis selanjutnya yang akan menggunakan variabel-variabel yang telah penulis teliti. Penulis menyarankan agar penulis selanjutnya dapat mengembangkan penelitian ini dengan baik tanpa menghilangkan unsur-unsur yang telah tertera pada laporan skripsi ini dan penulis selanjutnya dapat menambahkan variabel-veriabel lain yang dapat mempengaruhi kinerja karyawan.

\section{DAFTAR PUSTAKA}

Afandi, P. (2018). Manajemen Sumber Daya Manusia (Teori, Konsep dan Indikator). Riau: Zanafa Publishing.

Fajar, T. (2020, Maret 12). Dipetik April 15, 2021, dari okefinance: https://economy.okezone.com/read/2020/03/11/320/2181872/11-7-instansipemerintah-dinilai-buruk-dalam-manajemen-kinerja-pns

Kasmir. (2016). MAnajemen Sumber Daya Manusia (Teori dan Praktik). Jakarta: Rajawali Press.

Krismiaji. (2020). Sistem Informasi Akuntansi Edisi 5. Yogyakarta: Unit Penerbit dan Percetakan Sekolah Tinggi Ilmu Manajemen YKPN.

Mulyadi. (2017). Sistem Akuntansi. Jakarta Selatan: Penerbit Salemba Empat.

Sugiyono. (2019). Metode Penelitian Kuantitatif Kualitatif dan $R \& D$. Bandung: ALFABETA. 